\title{
Aspectos anatomopatológicos da miopatia peitoral profunda em frangos de corte abatidos sob inspeção sanitária
}

\section{Gross and histopathological lesions of deep pectoral myopathy in broilers slaughtered under sanitary inspection}

\author{
Thaís Badini Vieira, ${ }^{*}$ Davi de Oliveira Almeida, ${ }^{*}$ Fernanda Martinez Xavier Alves, ${ }^{*}$ Robson Maia Franco, ${ }^{* *}$ \\ Cláudia Leal Andrade, ${ }^{* * *}$ Rogério Tortelly****
}

\begin{abstract}
Resumo
A miopatia peitoral profunda é uma enfermidade poligênica, caracterizada pela necrose do músculo supracoracóideo de frangos de corte e perus comerciais. A lesão é causada pela isquemia local, resultado do intenso melhoramento genético dessas aves, na tentativa de selecionar animais com musculatura peitoral bem desenvolvida. Neste estudo foram realizadas descrições macroscópicas e microscópicas de lesões consideradas típicas de miopatia peitoral profunda. Foram colhidos fragmentos do músculo supracoracóideo de 17 frangos de corte e do músculo peitoral de um frango. Macroscopicamente, a musculatura afetada apresentava coloração variada, sendo observadas as cores vermelho-púrpura, amarelo-claro ou verde, e ainda, atrofia acentuada. Nestes últimos, a textura era ressecada e friável, enquanto nos casos em que a coloração era vermelho-púrpura, notava-se uma aparência edematosa da musculatura. Microscopicamente, as alterações eram representadas por extensas áreas de necrose de fibras, com mineralização e fragmentação de miofibras. Em duas amostras eram evidentes a calcificação de paredes vasculares e a degeneração de nervos. Em uma amostra era marcante o processo inflamatório granulomatoso, rico em células gigantes multinucleadas. De acordo com os resultados obtidos, pode-se afirmar que, independentemente dos aspectos apresentados ao exame externo, as alterações microscópicas foram constantes, tornando possível o diagnóstico da enfermidade através dos aspectos macroscópicos apresentados.
\end{abstract}

Palavras-chave: miopatia peitoral profunda, frangos de corte, histopatologia.

\begin{abstract}
Deep pectoral myophaty is a polygenic disease characterized by a supracoracoid muscle necrosis in broilers and commercial turkeys. The lesion is caused by a local ischemia, result of the higher genetic research in these birds, trying to select a developed pectoral muscle. In this study was done a macroscopic and microscopic description of typical deep pectoral myophaty lesions. Samples Were gotten from supracoracoid muscle in seventeen broilers, and the pectoral muscle in one chicken. Macroscopically, the affected musculature showed a variation color, being observed a red-purple, light-yellow or green, with high atrophy. In that last case the texture was dry and friable, beside in the other cases, with red-purple color, the musculature was edematous. Microscopically the alterations showed high fiber necrosis areas with mineralization and fragmentation of the myofibers. In two samples were evident the calcification of the vascular walls and the degeneration of the nerve. A hemorrhagic focus and a slight mixed diffuse inflammatory process infiltrated the lesion. In one sample there was a marked granulomatoseus inflammatory process rich in multinucleate gigantic cells. According to these results, we can to affirm that independently of the aspects on external exam, the microscopically alterations were constantly, became possible the diagnosis of the disease through the macroscopic aspects.
\end{abstract}

Keywords: deep pectoral myopathy, broilers, histopathology.

\section{Introdução}

A tecnologia de produtos elaborados de aves evoluiu de maneira bastante rápida, aumentando, com isso, a preocupação com a qualidade das suas matérias-primas.
Até o início da última década, a indústria avícola preocupavase somente com a qualidade estética das carcaças e cortes. No entanto, nos últimos anos, os avanços tecnológicos mudaram esta situação. Tornou-se necessária a preocupação

* Pós-Graduação em Medicina Veterinária - Higiene Veterinária e Processamento Tecnológico de Produtos de Origem Animal (Doutorado) Faculdade de Veterinária - Universidade Federal Fluminense, Niterói, RJ, Brasil. Email: thais.badini@ig.com.br.

** Departamento de Tecnologia de Alimentos, Universidade Federal Fluminense, Niterói, RJ, Brasil. E-mail: robsonmf@vm.uff.br

*** Veterinária autônoma.

*** Departamento de Patologia da Universidade Federal Fluminense, Niterói, RJ, Brasil.

Autor para correspondência: Rogério Tortelly.E-mail: rtortel@microlink.com.br 
em relação à qualidade funcional das matérias-primas, como forma de evitar perdas econômicas e garantir a qualidade final desejada, visando sempre a satisfação dos consumidores (Olivo, 2004).

A evolução na produção de carne de aves permitiu uma grande diversificação de produtos, com maior elaboração de itens de conveniência, praticidade e valor agregado, em detrimento da comercialização de carcaças inteiras. Os músculos da região do peito das aves apresentam grande valor comercial e, entre os produtos atualmente oferecidos, o filezinho de peito tem grande aceitação entre os consumidores. Entretanto, a intensa seleção genética das linhagens, pela necessidade econômica de abater aves em menor tempo de vida e com rápido ganho de peso, tem causado comportamentos fisiológicos anormais, com danos ao tecido muscular, como a miopatia peitoral profunda (Pereira et al., 2005).

Esta enfermidade foi descrita pela primeira vez em criações de perus no Oregon/USA em fêmeas com mais de 10 meses de idade, sendo também relatada em criações de matrizes e frangos de corte (Jones et al., 1978).

A miopatia peitoral profunda, também chamada de doença do músculo verde, é uma enfermidade poligênica (Harper et al, 1983), caracterizada pela necrose do músculo supracoracóideo de frangos de corte e perus comerciais (Wight e Siller, 1980; Santiago, 2001). A lesão é causada pela isquemia local, resultado do intenso melhoramento genético dessas aves, na tentativa de selecionar animais com musculatura peitoral bem desenvolvida (Siller, 1985; Wilson et al., 1990). A falta de oxigenação muscular é facilitada pela pequena fáscia muscular, que não acomoda o crescimento do músculo durante exercícios vigorosos, quando o mesmo aumenta $20 \%$ de seu tamanho (Siller, 1985). No Brasil, esta miopatia é um problema real na linha de abate de frangos, pois a sua prevalência é representativa, acarretando no descarte de uma parte da musculatura valorizada pelo mercado. Em um estudo realizado durante três meses, observando 7,6 milhões de carcaças de frango de corte (com idade de, aproximadamente, sete semanas) e 377 mil carcaças de galinhas poedeiras adultas pesadas (em fase de descarte), de diferentes linhagens, a ocorrência da enfermidade foi de $0,096 \%$ e de $7,2 \%$, respectivamente (Berto Filho e Olivo, 2004). Em outros países, Pastuszczak e Uradzinsk (2002) relataram a ocorrência da miopatia em $15,6 \%$ dos perus abatidos na Polônia, resultando na perda de mais de duas toneladas de carne.

De acordo com as técnicas de inspeção de aves do Brasil, baseadas na Normativa 210, que aprova o Regulamento Técnico da Inspeção Tecnológica e Higiênico Sanitária da Carne de Aves, o músculo supracoracóideo é exposto apenas quando a carcaça requer avaliação mais detalhada no Departamento de Inspeção Final (DIF) ou na sala de desossa (Brasil, 1998), o que pode reduzir significantemente a estimativa real da ocorrência das lesões.

Segundo Berto e Olivo (2004), a miopatia peitoral profunda é freqüentemente observada em matadouros, porém é comumente confundida pelos inspetores como sendo um hematoma decorrente do manejo e transporte inadequados.

Macroscopicamente, as lesões podem ser uni ou bilaterais (Wight e Siller, 1980; Merck, 1991; Crespo e Shivaprasad, 2003), estando o terço médio do músculo supracoracóideo mais comumente e severamente acometido (Merck, 1991;
Barragán, 2006), sendo a porção caudal à área necrótica pálida e distintamente atrofiada (Santiago, 2001). Nas lesões agudas, todo músculo peitoral profundo está amolecido, pálido e edematoso com extensas áreas de necrose (Crespo e Shivaprasad, 2003), por vezes coberto por uma camada fibrinosa e hemorrágica (Barragán, 2006). Em lesões subagudas, o edema desaparece, e o músculo necrótico tornase mais proeminente e seco, com áreas esverdeadas. Nas lesões crônicas, o músculo está atrofiado e uniformemente verde, seco, friável e envolvido por uma cápsula fibrosa, podendo tornar-se uma cicatriz (Barragán, 2006; Crespo e Shivaprasad, 2003).

A musculatura afetada apresenta alteração de coloração que varia do amarelo-claro ao verde, com textura fibrosa e seca e aparência edematosa (Santiago, 2001; Berto Filho e Olivo, 2004) ou hemorrágica (Merck, 1991).

Histologicamente, as fibras musculares sofrem necrose e se apresentam anucleadas, desprovidas de células inflamatórias e circundadas por uma cápsula fibrosa (Wight e Siller, 1980). Ao redor deste tecido necrótico, há reação inflamatória com heterófilos, macrófagos e células gigantes; em casos crônicos pode-se encontrar uma cápsula fibrosa. No músculo adjacente ao tecido necrosado as fibras podem estar atrofiadas ou substituídas por gordura (Crespo e Shivaprasad, 2003). Segundo Page e Fletcher (1975), as lesões histológicas variam de esteatose à perda das estriações, fragmentação das fibras e deposição mineral. Pastuszczak et al. (2002) notaram alterações semelhantes no músculo peitoral, porém, menos intensas do que as relatadas no músculo supracoracóide, o qual é o principal músculo afetado.

Apesar de determinar poucos problemas clínicos, o ônus torna-se maior devido ao descarte da carcaça ou parte desta (Merck, 1991). Além disso, a presença desta enfermidade poderá afetar a qualidade final da carne e produtos derivados de aves (Berto Filho e Olivo, 2004).

Assim, através deste estudo, objetiva-se descrever os aspectos macroscópicos e microscópicos da miopatia peitoral profunda em frangos de corte, a fim de facilitar o diagnóstico da enfermidade pelo serviço de inspeção.

\section{Material e métodos}

Foram colhidos fragmentos do músculo supracoracóide que apresentavam alterações macroscópicas sugestivas de miopatia peitoral profunda de 17 aves e do músculo peitoral de uma ave, que tinham em média 45 dias e $2,5 \mathrm{~kg}$, em abatedouros sob inspeção sanitária federal. Para a realização do exame histopatológico, as amostras foram mantidas em frangos contendo formol a $10 \%$ e encaminhados ao Laboratório de Anatomia Patológica Veterinária da Universidade Federal Fluminense, onde foi realizado o processamento pelas técnicas habituais de inclusão em parafina e coloração com hematoxilina-eosina (H.E.), de acordo com Meyer e Franks (1986).

\section{Resultados e discussão}

Das 18 amostras colhidas, apenas uma apresentou a enfermidade também no músculo peitoral. As lesões encontradas localizavam-se principalmente no músculo supracoracóideo (filezinho), uni ou bilateralmente como citado 
por Wight e Siller (1980); Merck (1991) e Crespo e Shivaprasad (2003). Assim como observado neste estudo, Pastuszczak et al. (2002) descreveram lesões de miopatia em músculo peitoral profundo. Tais resultados tornam-se importantes, pois confirmam a assertiva de que estas alterações não estão presentes somente no músculo supracoracóideo. Macroscopicamente, a musculatura afetada apresentava coloração variada, sendo observadas as cores vermelho-púrpura, amarelo-claro ou verde, além de atrofia acentuada como descrito por Santiago (2001) e Berto Filho e Olivo (2004). Neste último, a textura era ressecada e friável, enquanto os casos em que a coloração era vermelho-púrpura notava-se aparência edematosa da musculatura. Segundo Crespo e Shivaprasad (2003), as lesões encontradas nesta pesquisa podem ser consideradas como crônica e aguda, respectivamente. Microscopicamente, as alterações eram representadas por extensas áreas de necrose de fibras com preservação da morfologia, independentemente do aspecto macro. Em alguns campos, percebia-se tanto mineralização como fragmentação de miofibras. Em duas amostras eram evidentes a calcificação de paredes vasculares e a degeneração de nervos. Focos de hemorragia e discreto processo inflamatório misto difuso infiltravam a lesão. Em um caso era marcante o processo inflamatório granulomatoso, rico em células gigantes multinucleadas. Na periferia da alteração era freqüente a presença de tecido fibrovascular e focos de regeneração. Tais alterações assemelham-se àquelas descritas por Page e Fletcher (1975) e Wight e Siller (1980), embora não tenha

\section{Referências}

BARRAGÁN, J. I. La enfermedad del músculo verde en pollos: un proceso casa vez más frecuente. Asociación Española de Ciencia Avícola. Documento eletrônico. Disponível em: <http://www.wpsa-aeca.com/ wpsa.php?boletin=1\&co digo=791 >Acesso em: 29 de abril 2006.

BERTO FILHO, R. Z:; OLIVO, R. Miopatia peitoral profunda em frangos. Revista nacional da carne, n. 330, agosto, 2004.

BRASIL, Normativa № 210, de 10 de novembro de 1998. Aprova o Regulamento Técnico da Inspeção Tecnológica e Higiênico Sanitária da Carne de Aves. Diário Oficial da República Federativa do Brasil, Brasília, DF, 1998.

CRESPO, R.; SHIVAPRASAD, H. L. Developmental, Metabolic, and other Noninfectious Disorders. In: SAIF, Y. M. Diseases of Poultry. 11th. lowa State Press, 2003.

HARPER, J. A; BERNIER, P. E.; THOMPSON-COWLEY, L. L. Early expression of hereditary deep pectoral myopathy in turkeys due to forced wing exercise. Poultry Science, v. 62, p. 2303-2308, 1983.

JONES, H. G. R.; RANDALL, C. J.; MILLS, C. P. J. A survey of mortality in three adult broiler breeder flocks. Avian Pathology, v. 7, p. 619-628, 1978.

MERCK. Manual de Veterinária: um manual de diagnóstico, tratamento, prevenção e controle de doenças para o veterinário / Editado por Clarence M. Fraser, 6. ed. São Paulo: Roca, 1991. p. 1490.

MEYER, D.J.; FRANKS, S.P. Clinical Cytrology Part 1: Management of Tissue Specimes. M.V.P., p. 440-445, 1986. ocorrido substituição das fibras por gordura, como citado por Crespo e Shivaprasad (2003). A existência do processo granulomatoso pode estar associado à contaminação bacteriana da lesão, podendo pôr em risco a saúde do consumidor, por serem potenciais causadoras de enfermidades transmissíveis por alimentos (ETA). Assim, a possibilidade da associação com contaminação bacteriana necessita de estudos mais abrangentes, a fim de identificar a importância desta miopatia como transmissora de agentes etiológicos causadores de enfermidades. Um outro fator importante está ligado às técnicas de inspeção de aves do Brasil, baseada na IN $n^{0} 210$, que determina que o músculo supracoracóideo seja exposto apenas quando a carcaça requerer avaliação mais detalhada no DIF ou na sala de desossa, possibilitando que algumas lesões passem despercebidas quando as aves são vendidas inteiras. Outrossim, tal ocorrência acarretará em prejuízos para o consumidor, visto que a lesão será identificada após o manuseio do produto. Para a indústria, as perdas estão relacionadas com a condenação do filezinho ou de carcaças inteiras, além da inutilização destas para a produção de carne mecanicamente separada (CMS).

\section{Conclusão}

De acordo com os resultados obtidos, pode-se afirmar que, independentemente dos aspectos apresentados ao exame externo, as alterações microscópicas foram constantes, tornando possível o diagnóstico da enfermidade através dos aspectos macroscópicos apresentados.

OLIVO, R. Atualidades na qualidade da carne de aves. Revista Nacional da Carne, n. 331, setembro, 2004.

PAGE, R. K.; FLETCHER, O. J. Myopathy of the deep pectoral muscle in broiler breeder hens. Avian Diseases, v. 19, n. 4, p. 814-821. 1975.

PASTUSZCZAK, M.; URADZINSKI, J. The prevalence of green muscle disease in turkeys from the Warmia and Mazury province of Poland. Pol. J. Vet. Sci. v. 5, n. 2, p. 57-61, 2002.

PASTUSZCAK, M.; URADZINSKI, J.; ROTKIEWICZ, T. Histopathological changes in green muscle disease of turkeys. Pol. J. Vet. Sci. v. 5, n. 2 , p. 63-70, 2002.

PEREIRA, R. A.; RODRIGUES, L. B.; ALLGAYER, M. C.; DICKEL, E. L.; SANTOS, L. R.; GABRIELE, E.; CARÍSSIMI, A. S. Miopatia peitoral profunda em frangos de corte. Veterinária em foco, v. 3, n. 1, p. 11-15, 2005.

SANTIAGO, H. L. Impact of Genetic selection on Skeletal Muscle in meat-type poultry. Mensagem recebido por: $\mathrm{Http}$ ://academic.uprm.edu/ hsantiago/ em 23 de fevereiro de 2005.

SILLER, W. G. deep pectoral myopathy: a penalty of successful selection for muscle growth. Poultry Science, v. 64, p. 1591-1595, 1985.

WIGHT, P. A.; SILLER, W. G. Pathology of deep pectoral myopathy of broilers. Veterinary Pathology, v. 17, n. 1, p. 29-39, 1980.

WILSON, B. W.; NIEBERG, P. S.; BUHR, R. J.; KELLY, B. J.; SHULTZ, F.T. Turkey muscle growth and focal myopathy. Poultry Science, v. 69, p. 1553-1562, 1990. 